Article

\title{
Exogenous ABA Induces Osmotic Adjustment, Improves Leaf Water Relations and Water Use Efficiency, But Not Yield in Soybean under Water Stress
}

\author{
Jin He ${ }^{1,2, *(\mathbb{D}, \text { Yi Jin }}{ }^{2}$, Jairo A. Palta ${ }^{3,4}$, Hong-Yan Liu ${ }^{1}$, Zhu Chen ${ }^{1}$ and Feng-Min Li ${ }^{1, * \mathbb{C}}$ \\ 1 College of Agriculture, Guizhou University, Guiyang 550025, China \\ 2 State Key Laboratory of Grassland Agro-Ecosystems, Institute of Arid Agroecology, School of Life Sciences, \\ Lanzhou University, Lanzhou 730000, China \\ 3 The UWA Institute of Agriculture and School of Agriculture \& Environment, The University of Western \\ Australia, LB 5005, Perth, WA 6001, Australia \\ 4 CSIRO Agriculture \& Food, Private Bag No. 5, Wembley, WA 6913, Australia \\ * Correspondence: hejin0811@163.com (J.H.); fmli@lzu.edu.cn (F.-M.L.)
}

Received: 8 June 2019; Accepted: 17 July 2019; Published: 18 July 2019

check for updates

\begin{abstract}
Abscisic acid (ABA) plays a central role in the plant response to water deficit by inducing stomatal closure to conserve water when the soil dries. Exogenous ABA was applied at 45 days after sowing (DAS) as a soil drench, the physiological and seed yield response of soybean to exogenous ABA were examined as the soil was drying. Three experiments were conducted using the drought-tolerant soybean cultivar Jindou 19, grown in pots at the Yuzhong Experimental Station of Lanzhou University, China. In experiment 1, plants were exposed to progressive soil drying and leaf ABA concentration, leaf photosynthesis rate, leaf relative water content (RWC) and osmotic adjustment (OA) were measured. In experiment 2, plants were under progressive soil drying and lethal leaf water potential was measured. In experiment 3, flower production and abortion, and grain yield were measured in plants under well-watered (WW), moderate (MWD) and severe water deficits (SWD). Exogenous ABA application increased ABA accumulation in leaves and reduced the rate of soil drying. It also increased leaf photosynthetic rate, stomatal conductance and transpiration rate at 7-10 days after withholding water. The intrinsic and instantaneous water use efficiency (WUE) was consistently higher with exogenous ABA than without $\mathrm{ABA}$ as the soil dried. Exogenous ABA increased OA when the leaf relative water content (RWC) decreased at eight days after withholding water, lowering the lethal leaf water potential by $0.4 \mathrm{MPa}$. Exogenous ABA reduced water use, increased WUE for grain yield under WW and MWD, and had no effect on flower number, flower abortion or grain yield in any water treatment. We concluded that (1) exogenous ABA induced OA, improved leaf photosynthetic rate, leaf water relations and desiccant tolerance, but did not benefit grain yield in soybean under water deficits; (2) exogenous ABA improved the WUE at the leaf level as soil drying and WUE for grain yield under moderate water deficit.
\end{abstract}

Keywords: osmotic adjustment; abscisic acid; water stress; water use efficiency; seed yield; Glycine max (L.) Merr

\section{Introduction}

The plant hormone abscisic acid (ABA) plays a central role in a plant's response to water deficit [1,2]. ABA is produced as soil dries by the roots and transported to the leaves through the xylem, which induces stomatal regulation to conserve water and this is considered just an 'early warning signal' [3,4]. 
The exogenous application of $\beta$-aminobutyric acid (BABA) or ABA to wheat grown in pots increased ABA production during soil drying, improving leaf water relations and desiccant tolerance, but did not increase grain yield $[5,6]$. However, field studies have shown that under moderate water restriction, exogenous application of ABA can increase grain yield in wheat [7] and sunflower [8], suggesting that the role of exogenous applications of $\mathrm{ABA}$ on generating grain yield under drought conditions is controversial. Thus, further studies were needed to determine the role of exogenous ABA application in yield formation. A previous study also showed that exogenous applications of ABA increased water use efficiency for grain yield $\left(W U E_{g}\right)$ in wheat, mainly because of a reduction in water use [6]. New released soybean cultivars, such as Zhonghuang 30 and Jindou 19 can accumulate more leaf ABA at high soil water content than the old ones, inducing stomatal regulation, improving leaf relative water content (RWC) and leaf desiccant tolerance as soil dries [9]. However, it is unknown whether accumulation of leaf $\mathrm{ABA}$ at high soil water content can improve grain yield and WUEg. It is also unknown whether at the leaf level, the intrinsic water use efficiency $\left.\left(W_{U E}\right)_{i}\right)$ and instantaneous WUE $\left(\mathrm{WUE}_{\text {inst }}\right)[10]$ can be improved by exogenous application of ABA to soybean.

Osmotic adjustment (OA) [11-14] is considered a useful trait for maintaining cell turgor as tissue water potential declines. New soybean cultivars such as Zhonghuang 30 and Jindou 19 with high OA had better leaf RWC and desiccant tolerance under drought conditions [9]. OA can also affect leaf desiccation tolerance in soybean $[15,16]$, because OA allows a further reduction in water potential without a complete turgor loss, and benefits for water uptake [17]. The $\mathrm{K}^{+}$uptake transporter 6 (KUP6) plays a major role in OA under drought conditions by balancing potassium homeostasis under the control of ABA [18]. However, the important question is whether increasing OA, which is associated with the accumulation of $A B A$, can improve leaf RWC and desiccation tolerance in soybean.

Three pot experiments were conducted to evaluate the effects of exogenous ABA, applied as a soil drench, on the physiology of the drought and yield of the drought-tolerant soybean cultivar Jindou 19. In the first experiment, leaf ABA concentration, photosynthesis rate, RWC and OA were measured in plants under progressive soil drying. In the second experiment, lethal leaf water potential was studied in plants under progressive soil drying. In the third experiment flower production and abortion, and grain yield were studied underwell-watered (WW) with soil water content at $70-90 \%$ field capacity (FC), moderate water deficit (MWD) at 45-55\% FC and severe water deficits (SWD) at 30-35\% FC.

\section{Material and Methods}

The three pot experiments were conducted between March and October 2012 at the Yuzhong Experimental Station of Lanzhou University, Yuzhong, China, using the drought-tolerant high-yielding soybean cultivar Jindou 19. Pots were $32 \mathrm{~cm}$ diameter $\times 26 \mathrm{~cm}$ high, filled with $9.5 \mathrm{~kg}$ of sieved turfy-soil-based substrate in a 3:1 turfy soil:perlite $(v / v)$ ratio, with a field capacity (FC) of $120 \%(w / w)$. $\mathrm{NH}_{4} \mathrm{NO}_{3}$ and $\mathrm{KH}_{2} \mathrm{PO}_{4}$ fertilizers were added to the dry soil of each pot at a rate of $220 \mathrm{~kg} \mathrm{~N} / \mathrm{ha}, 130 \mathrm{~kg}$ $\mathrm{P} / \mathrm{ha}$ and $164 \mathrm{~kg} \mathrm{~K} / \mathrm{ha}$. Seeds were soaked for $600 \mathrm{~s}$ in water containing $5 \mathrm{~g} \mathrm{~L}^{-1}$ carbendazim to prevent a fungus infection. Then six seeds were sown at middle by hand in each pot with $3-4 \mathrm{~cm}$ depth. The plants were initially grown under a rainout shelter before they were transferred to a growth chamber. After germination and when the plants were at V1 stage, the seedlings were thinned to three plants per pot. All pots were weighed and watered daily to maintain the soil water content in each pot at $80 \% \mathrm{FC}$. A layer of perlite of about $1.5 \mathrm{~cm}$ thick was used to cover the soil surface in each pot to minimize soil evaporation. There were a total of 126 pots in the three experiments.

\subsection{ABA Treatment for All Experiments}

ABA ( \pm -cis, trans abscisic acid, Sigma-Aldrich, Steinheim, Germany) was dissolved in 5-10 mL ethanol, further diluted with distilled water and then applied as a soil drenching at $10 \mu \mathrm{M}$ ABA soil concentration to half of the pots (63 pots) one day before (day 0, 08:00 PM) the watering treatments were imposed at $\mathrm{V} 4$ stage, 45 days after sowing (DAS). The treatment without ABA was supply with 5-10 mL ethanol with distilled water. 


\subsection{Experiment 1}

Three days before the water regimes were imposed and when plants were at the V4 stage, 45 days after sowing (DAS), 72 pots with three plants were transferred from the rainout shelter to a growth chamber. The growth chamber was maintained at day/night temperatures of $22 / 15{ }^{\circ} \mathrm{C}, 50 \% \pm 5 \%$ relative humidity (RH) and $300 \mu \mathrm{mol} \mathrm{m}^{-2} \mathrm{~s}^{-1}$ photosynthetic photon flux density (PPFD) at the canopy level for $14 \mathrm{~h}$ in each day.

Two ABA applications, 0 and $10 \mu \mathrm{M}$ ABA and two watering treatments, well-watered (WW) with SWC maintained at $80-90 \%$ FC and water stressed (WS) were imposed at the V4 stage when the palnst were 45 DAS until all available water were exhausted. Each treatment combination consisted of 18 pots (three replications $\times$ six samplings for a total of 72 pots). One day before the water was withdrawn and at 20:00 h, the exogenous ABA was applied as soil drenching when plants were at the V4 stage. The pots were weighed daily to determine the SWC. After the ABA applications and two water treatments were imposed, measurements of leaf relative water content (RWC), leaf photosynthesis rate (Pn), stomatal conductance $(g s)$, transpiration rate $(\mathrm{Tr})$ and leaf water potential ( $\left.\Psi_{\text {leaf }}\right)$ were measured daily on a fully-expanded leaf, often the third leaf from the top. Measurements of $\mathrm{Pn}$, gs and Tr were measured between 08:30 and 10:30 h BST with a Li-6400 portable photosynthesis system (Li-Cor, Lincoln, NE, USA), the light intensity, flow rate, RH and leaf temperature were 800 PPFD, $500 \mu \mathrm{mol} \mathrm{s}^{-1}, 50 \%$ and $25^{\circ} \mathrm{C}$, respectively. Measurements of leaf RWC and $\Psi_{\text {leaf }}$ were made on the same leaf. $\Psi_{\text {leaf }}$ was measured with a pressure chamber (PMS Instrument Co, Albany, OR, USA) following the precautions recommended by Turner [19]. The methods used to determine leaf RWC as followed: First, two leaf discs (5 mm in diameter) were sampled and weighed immediately to obtain the fresh weight (FW), then the discs were placed in tubes with freshly-distilled water for $8 \mathrm{~h}$ under $10 \mu \mathrm{mol} \mathrm{m}{ }^{-2} \mathrm{~s}^{-1}$ PPFD, surface dried with filter paper and weighed to obtain the saturated weight (SW), then dried it at $80^{\circ} \mathrm{C}$ in a forced-draught oven for $24 \mathrm{~h}$ to obtain the dry weight (DW). The leaf RWC was calculated as:

$$
\mathrm{RWC}=[(\mathrm{FW}-\mathrm{DW}) /(\mathrm{SW}-\mathrm{DW})] \times 100
$$

The values of leaf RWC were expressed as a percentage of the controls. Intrinsic water use efficiency $\left(\mathrm{WUE}_{\mathrm{i}}\right.$ ) was estimated as Pn/gs while and instantaneous WUE (WUE $\mathrm{inst}_{\text {) }}$ ) as Pn/Tr.

Three pots from each ABA application $\times$ water treatment combination were sampled on six occasions after withholding water. The first sampling (H1), was made one day after the treaments commenced. Sampling two (H2) when gs in plants without exogenous ABA application significantly decreased. Sampling three (H3) when SWC in the pots had declined to $~ 55 \%$ FC, but leaf RWC had not significantly decreased. Sampling four (H4) when leaf RWC significantly decreased. Sampling five (H5) when temporary wilting was observed and sampling six (H6) when permanent wilting ocurred. Permanent wilting was defined when leaves that wilt during the day did not recover during the night following rewatering [20]. At each sampling, the fully expanded leaves used to measure $\mathrm{Pn}, g s$ and $\mathrm{Tr}$ were collected and frozen immediately in liquid nitrogen for osmotic potential and ABA determination.

The osmotic potential (OP) was measured using a vapor pressure osmometer (Model 5520; Wescor Inc., Logan, UT, USA). The OP at full turgor $\left(\mathrm{OP}_{100}\right)$ was estimated from the measured OP and RWC such that $\mathrm{OP}_{100}=\mathrm{OP} \times(\mathrm{RWC} / 100)$ [21]. Samples were taken on three occasions, and $\mathrm{OA}$ at each harvest was calculated as the difference between $\mathrm{OP}_{100}$ in well-watered (H1) and $\mathrm{OP}_{100}$ at $\mathrm{H} 2-\mathrm{H} 6$.

The upper fully expanded leaves that used to measure $\mathrm{Pn}, g s$ and $\mathrm{Tr}$ were collected from the third leaf from the top for ABA determination. Extraction and purification of ABA from the leaves was carried out following the protocol described by [22]. Briefly, leaf samples were finely ground in liquid nitrogen using a mortar and pestle before extraction for $4 \mathrm{~h}$ in ice-cold $80 \%$ methanol $(v / v)$ containing $1 \mathrm{mM}$ butylated hydroxytoluene to avoid oxidation. The extracts were centrifuged at $10,000 \mathrm{~g}$ for $15 \mathrm{~min}$ at $4{ }^{\circ} \mathrm{C}$. The supernatant was removed, and the residues re-suspended using $1 \mathrm{~mL}$ of the same ice-cold extraction solution, extracted at $4{ }^{\circ} \mathrm{C}$ for $1 \mathrm{~h}$, and centrifuged again at $10,000 \mathrm{~g}$ for $15 \mathrm{~min}$ at $4{ }^{\circ} \mathrm{C}$. The two supernatants were combined and filtered with Chromosep C18 columns (C18 Sep-Park Cartridge, 
Waters, Milford, MA, USA) to collect the efflux, which was dried by evaporation with nitrogen. The residue was dissolved in $2 \mathrm{~mL}$ phosphate-buffered saline (PBS) containing $0.1 \%(v / v)$ Tween 20 and $0.1 \%(w / v)$ gelatin $(\mathrm{pH} 7.5)$. Analysis was carried out by an enzyme-linked immunosorbent assay (ELISA) as per the protocol described by Yang et al. [23]. The mouse monoclonal antigen and antibody against $\mathrm{ABA}$ and the immunoglobulin G-horseradish peroxidase used in the ELISA were produced at the Phytohormones Research Institute, China Agricultural University, Beijing, China. The specificity of the monoclonal antibody was confirmed and nonspecific inhibitors excluded [23].

\subsection{Experiment 2}

Twelve pots with three plants each were used to determine the effect of a $10 \mu \mathrm{M}$ exogenous application of ABA on the lethal leaf water potential. Three days before the watering regimes were imposed at the V4 stage, $45 \mathrm{DAS}$, pots were transferred from the rainout shelter to a growth chamber. The growth chamber was maintained at day/night temperatures of $22 / 15^{\circ} \mathrm{C}, 50 \% \pm 5 \%$ relative humidity (RH) and $300 \mu \mathrm{mol} \mathrm{m}^{-2} \mathrm{~s}^{-1}$ photosynthetic photon flux density (PPFD) at the canopy level for $14 \mathrm{~h}$ in each day. One day (08:00 PM) before the watering regimes were imposed at the V4 stage, exogenous ABA was applied as soil drenching at 20:00 h. Watering was withdrawn at 45 DAS to induced water deficits, and 15 days after water was withdrawn measurements of $\Psi_{\text {leaf }}$ were commenced. Lethal $\Psi_{\text {leaf }}$ was determined when leaves began to show extensive necrotic areas as they died as the $\Psi_{\text {leaf }}$ of the last living leaf.

\subsection{Experiment 3}

Forty-two pots with three plants each were used to determine the effects of $10 \mu \mathrm{M}$ exogenous ABA on flower number, flower abortion, grain yield and yield components under well-watered conditions (WW) with SWC maintained at 70-90\% FC; moderate water deficits (MWD) with SWC at $45-55 \%$ FC and severe water deficits (SWD) with SWC at 30-35\% FC. At 45 DAS, two ABA applications, 0 and $10 \mu \mathrm{M}$ ABA and three watering treatments, well-watered (WW) with SWC maintained at $80-90 \%$ FC, moderate water deficits (MWD) with SWC at $45-55 \%$ FC and severe water deficits (SWD) with SWC at $30-35 \%$ FC were imposed. The pots were weighed daily and watered to the treatment water levels. Water use during plant growth was calculated from the water additions from sowing to physiological maturity. Flowers were tagged from the first flower, with new flowers tagged every two days so that flower number could be determined. Whole plants were harvested at physiological maturity, divided into leaves, stem and pods, dried at $80^{\circ} \mathrm{C}$ for $24 \mathrm{~h}$, and weighed. The pod number at physiological maturity was determined. The following variables were calculated: Water use efficiency (WUE) for grain yield $=$ grain dry weight/water use, and flower abortion $=100-($ pod number/flower number $)$ $\times 100 \%$.

\subsection{Statistical Analysis}

The Duncan test was used to compare the rate of soil drying and the soil water content of six harvest times with or without exogenous ABA in experiment 1 and the different of lethal leaf water potential with or without exogenous ABA in experiment 2. Two-way analyses of variance (ANOVA) were conducted using GenStat 17th edition (V-International Ltd., Rothamsted, UK) to analyze the measured variables in Experiment 3. In two-ways ANOVA, the water and chemical treatments were considered fixed factors, and the random factor was block (replicate).

\section{Results}

\subsection{Soil Drying, Leaf ABA Concentration, Photosynthesis and WUE at the Leaf Level}

Exogenous ABA significantly reduced the rate of soil drying by $4.6 \%$ (Table 1), especially in the first ten days after ABA was applied (Figure 1). As the soil dried to 16\% field capacity (FC), 14 days after withholding water, accumulation of $\mathrm{ABA}$ in the leaves increased from about $16 \mathrm{nmol} \mathrm{g}^{-1}$ dry 
weight (DW) on the first day after withholding water to $50 \mathrm{nmol} \mathrm{g}^{-1} \mathrm{DW}$. Exogenous application of ABA increased accumulation of ABA in the leaves from about $21 \mathrm{nmol} \mathrm{g}^{-1} \mathrm{DW}$ on the first day after withholding water to $62 \mathrm{nmol} \mathrm{g}^{-1} \mathrm{DW}$, as the soil dried to $15 \% \mathrm{FC}, 15$ days after withholding water (Figure 2). Exogenous ABA applications under well-watered conditions, initially increased leaf ABA concentration to $41 \mathrm{nmol} \mathrm{g}^{-1} \mathrm{DW}$ at 10 days after withholding water but after it decreased with time (Figure 2). Exogenous ABA applications under well-watered conditions, reduced photosynthesis rate (Pn) by $42.5 \%$, stomatal conductance $(g s)$ by $75.4 \%$ and transpiration rate $(\mathrm{Tr})$ by $60.1 \%$ during the first five days after application, but after that time $\mathrm{Pn}, g s$ and $\mathrm{Tr}$ had a full recovery (Figure 3). Intrinsic water use efficiency (WUE $_{\mathrm{i}}$ ) and instantaneous WUE (WUE $\mathrm{Wnst}_{\mathrm{i}}$ ) increased by $149.9 \%$ and $61.4 \%$ respectively in the first five days after the exogenous applications of ABA (Figure 3). As the soil was drying, Pn in plants in which exogenous ABA was applied increased by $160 \%$ on average from $7-10$ days after withholding water. gs and Tr also increased by $135 \%$ and $116 \%$ on average, respectively from 8-10 days (Figure $3 \mathrm{~A}-\mathrm{C}$ ). WUE $_{\mathrm{i}}$ with exogenous ABA application (59.2 on average) was significantly higher $(p<0.001)$ than without exogenous ABA application (34.1 on average) during the experiment. $W_{U E} E_{\text {inst }}$ with exogenous ABA application $(2.72$ on average) was significantly higher $(p<0.001)$ than without exogenous ABA application (1.72 on average) during the experiment (Figure 3D,E).

Table 1. The rate of soil drying, soil water content at each harvest, and the number of days after withholding water until the initial decrease in relative water content (H4), temporary wilting (H5) and permanent wilting (H6) in soybean cultivar Jindou 19 (JD) with (+ABA) and without (-ABA) $10 \mu \mathrm{M}$ exogenous ABA. Values are the mean \pm SE $(n=3)$. Means within a column with a different letter are statistically different at $p=0.05$. H1: One day after the water and chemical treatments; H2: Stomatal conductance significantly decreased without exogenous ABA; H3: Soil water content declined at about $55 \%$ field water capacity (FC).

\begin{tabular}{|c|c|c|c|c|c|c|c|c|c|c|}
\hline \multirow[t]{2}{*}{$\begin{array}{l}\text { Chemical } \\
\text { Treatment }\end{array}$} & \multirow[t]{2}{*}{$\begin{array}{c}\text { Rate of Soil } \\
\left.\text { Drying ( } \% \mathbf{h}^{-1}\right) \\
\end{array}$} & \multicolumn{6}{|c|}{ Soil Water Content (\% FC) } & \multicolumn{3}{|c|}{ Days After Withholding Water } \\
\hline & & H1 & H2 & H3 & H4 & H5 & H6 & H4 & H5 & H6 \\
\hline$-\mathrm{ABA}$ & $0.22 \mathrm{a}$ & $85.4 \pm 0.3 a$ & $66.2 \pm 0.9 \mathrm{a}$ & $54.7 \pm 1.2 \mathrm{a}$ & $33.5 \pm 1.2 \mathrm{a}$ & $20.0 \pm 0.8 \mathrm{a}$ & $16.1 \pm 0.9 \mathrm{a}$ & 8 & 12 & 14 \\
\hline$+\mathrm{ABA}$ & $0.21 \mathrm{~b}$ & $84.6 \pm 0.7 \mathrm{a}$ & $66.2 \pm 0.5 \mathrm{a}$ & $54.6 \pm 1.3 \mathrm{a}$ & $29.1 \pm 2.3 b$ & $18.5 \pm 1.3 \mathrm{a}$ & $15.1 \pm 1.1 \mathrm{a}$ & 10 & 13 & 15 \\
\hline
\end{tabular}

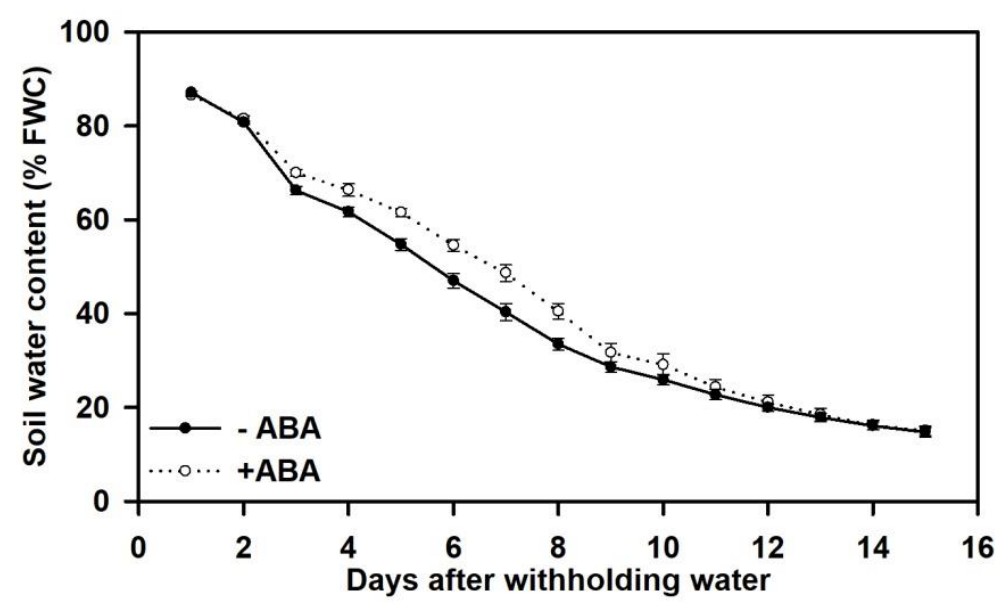

Figure 1. Changes in soil water content over time (days) after withholding water. One day before withholding water, plants were pretreated with (+ABA) or without (-ABA) $10 \mu \mathrm{M}$ exogenous ABA. Values are the mean $\pm \operatorname{SE}(n=3)$. 


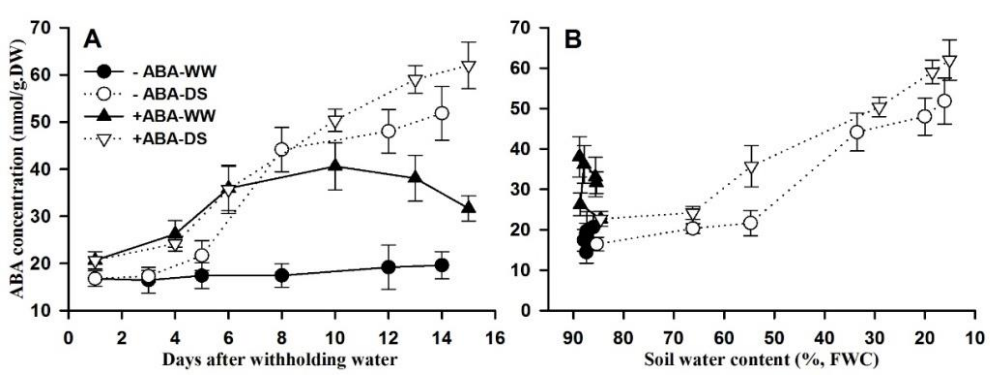

Figure 2. Changes in leaf ABA concentration over time (days) after withholding water (A) and with soil water content $(\mathbf{B})$ in the soybean cultivar Jindou 19 (JD) treated with (+ABA) and without (-ABA) $10 \mu \mathrm{M}$ exogenous ABA. Values are means $\pm \mathrm{SE}(n=3)$.

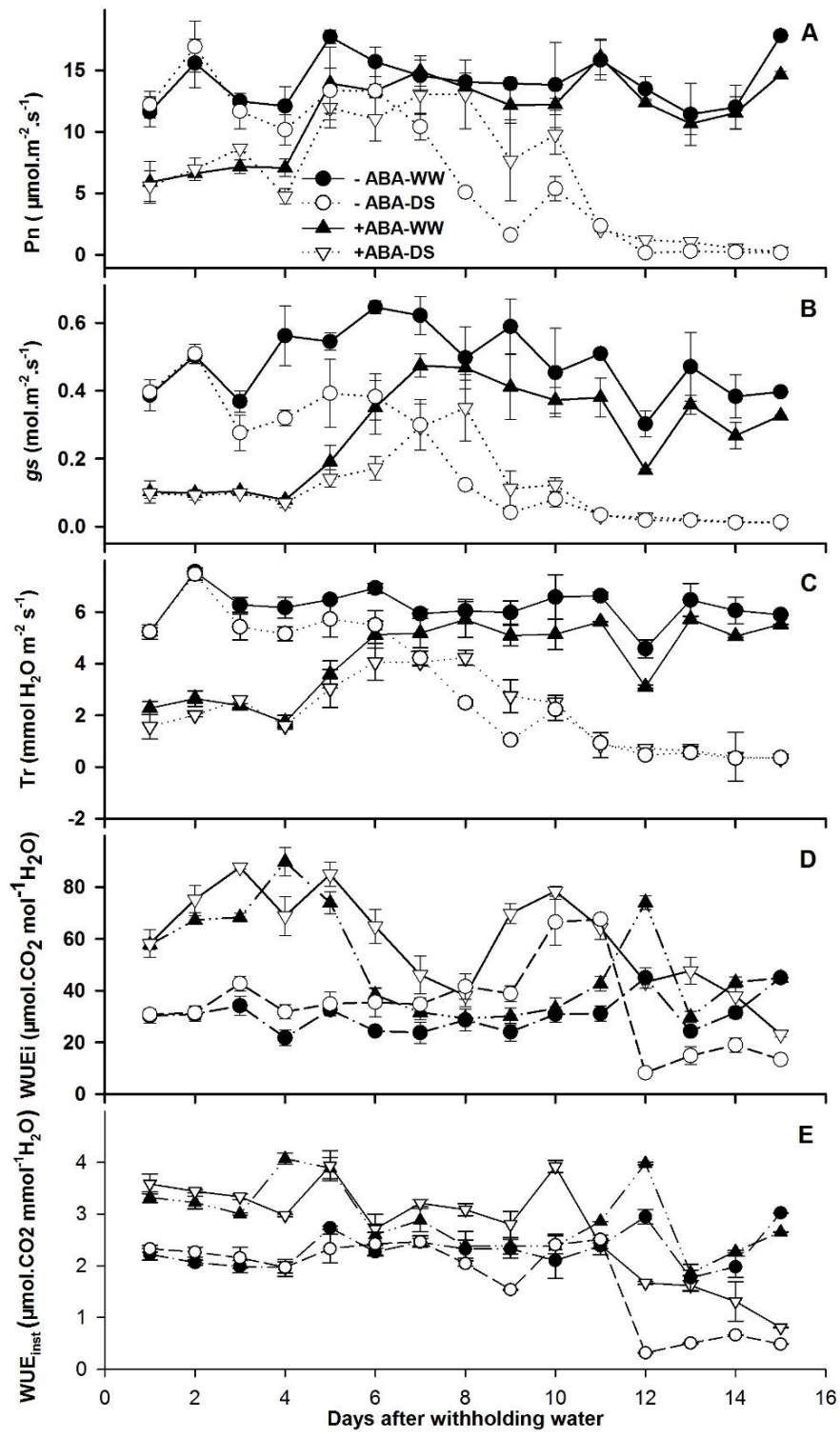

Figure 3. Changes in (A) photosynthetic rate (Pn), (B) stomatal conductance $(g s),(\mathbf{C})$ transpiration rate $(\mathrm{Tr})$ and $(\mathbf{D})$ intrinsic water use efficiency $\left(\mathrm{Pn} / \mathrm{gs}, \mathrm{WUE}_{\mathrm{i}}\right)$ and $(\mathbf{E})$ instantaneous WUE (Pn/Tr, WUE $\mathrm{E}_{\text {inst }}$ ) over time (days) after withholding water in the soybean cultivar Jindou 19 (JD). One day before withholding water, plants were pretreated with (+ABA) or without (-ABA) $10 \mu \mathrm{M}$ exogenous ABA. Values are means \pm SE $(n=3)$. 


\subsection{Leaf Water Relations, Desiccant Tolerance and Osmotic Adjustment}

The SWC decreased as the soil was drying and $\Psi_{\text {leaf }}$ and leaf RWC also decreased with time. When leaf RWC decreased, plants in which exogenous ABA was applied had significantly lower $(p<0.001)$ SWC $(29.1 \%$ FC) than those in which exogenous ABA was not applied (33.5\% FC; Table 1, Figure 4). The reduction in leaf RWC with decreasing $\Psi_{\text {leaf }}$ was slower under exogenous application of ABA than without ABA application (Figure 5). The lethal $\Psi_{\text {leaf }}$ with exogenous ABA applied was significantly lower $(p<0.001 ;-3.5 \mathrm{MPa}$ ) than without exogenous ABA applied (-3.1 MPa; Figure 6). OA increased from $0.21 \mathrm{MPa}$ to $0.81 \mathrm{MPa}$ as SWC decreasing; $\mathrm{OA}$ was highest $(0.81 \mathrm{MPa})$ when leaf RWC significantly decreased ( $p<0.05$, sample 4 ) under exogenous application of ABA. For without $\mathrm{ABA}$ application the highest $\mathrm{OA}$ was $0.4 \mathrm{MPa}$ (Figure 7) at sample 4.

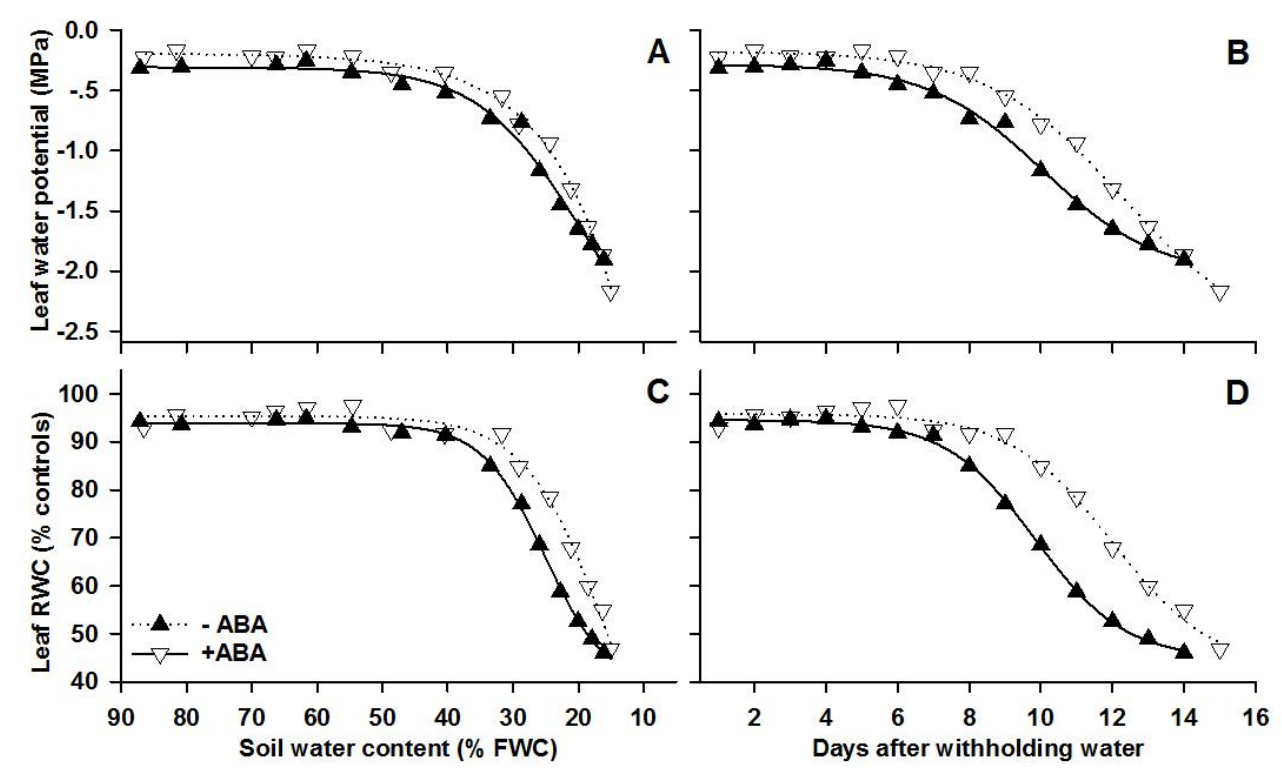

Figure 4. Changes in leaf water potential (LWP) and leaf relative water content (RWC) with soil water content $(\mathbf{A}, \mathbf{C})$ and days after withholding water $(\mathbf{B}, \mathbf{D})$ in the soybean cultivar Jindou 19 (JD). One day before withholding water, plants were pretreated with (+ABA) or without (-ABA) $10 \mu \mathrm{M}$ exogenous ABA. Values are means \pm SE $(n=3)$.

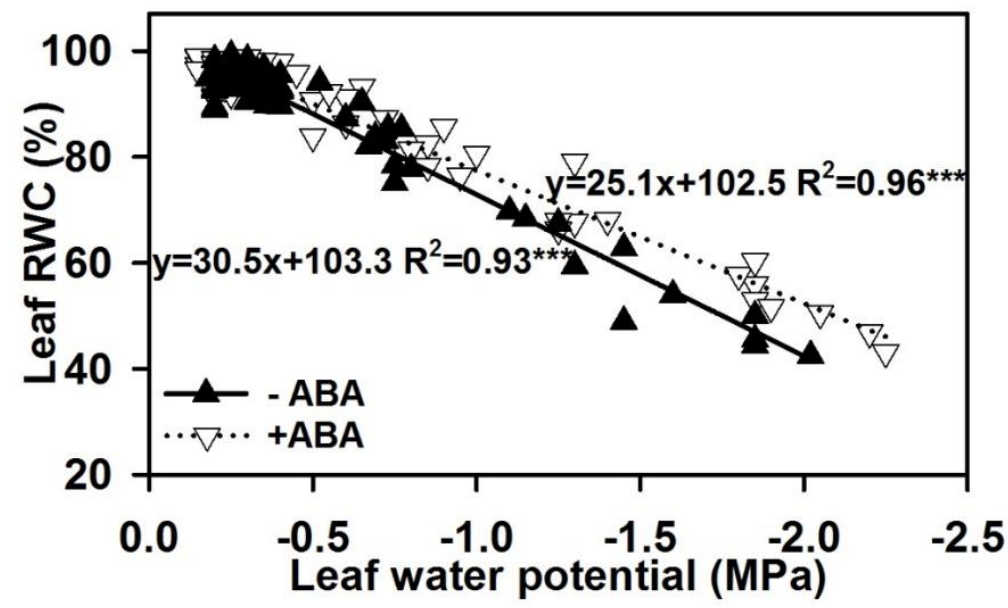

Figure 5. The effects of $10 \mu \mathrm{M}$ exogenous ABA on leaf relative water content (RWC) changed with leaf water potential decreasing in the soybean cultivar Jindou 19 (JD). One day before withholding water, plants were pretreated with (+ABA) or without (-ABA) $10 \mu \mathrm{M}$ exogenous ABA. 


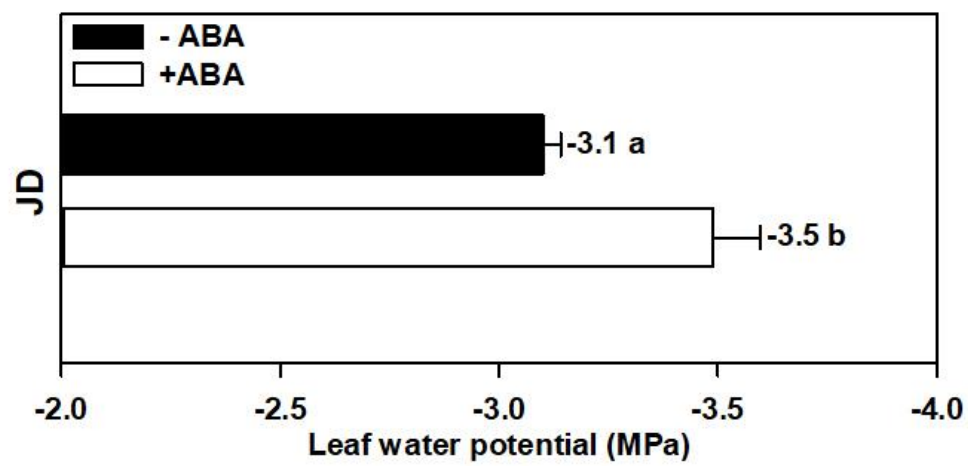

Figure 6. The effect of $10 \mu \mathrm{M}$ exogenous ABA on lethal leaf water potential of the soybean cultivar Jindou 19 (JD). One day before withholding water, plants were pretreated with (+ABA) or without $(-\mathrm{ABA}) 10 \mu \mathrm{M}$ exogenous ABA. Values are means $\pm \mathrm{SE}(n=6)$.

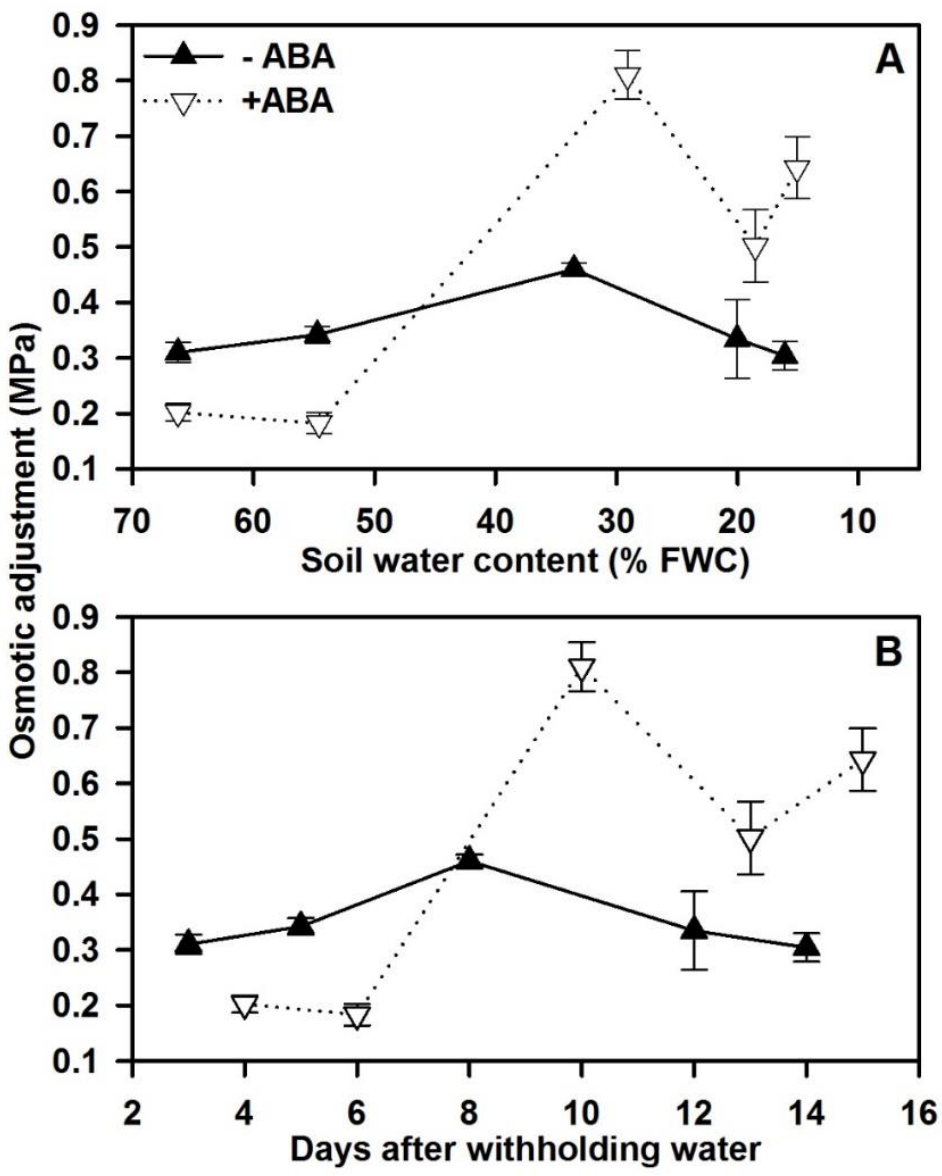

Figure 7. Changes in leaf osmotic adjustment (OA) with soil water content (A) and days after withholding water (B) in the soybean cultivar Jindou 19 (JD). One day before withholding water, plants were pretreated with (+ABA) or without $(-\mathrm{ABA}) 10 \mu \mathrm{M}$ exogenous ABA. Values are means $\pm \mathrm{SE}(n=3)$.

\subsection{Flower and Pod Numbers, Yield, Yield Components, and WUE}

Exogenous application of ABA had no effect on the number of flowers and pods or the number of flower aborted under any of the three watering treatments (Figure 8, Table S1). Water stress significantly reduced seed number by $30 \%$ for MWD and $57 \%$ for SWD, hundred-grain weight by $2.2 \%$ for MWD and $12.6 \%$, grain yield by $31.5 \%$ for MWD and $62.4 \%$ for SWD (Figure 9 ). Water stress significantly reduced water use by $33.8 \%$ for MWD and $56.2 \%$ SWD, harvest index by $3.6 \%$ for MWD and $6.9 \%$ for SWD (Figure 9). Exogenous application of ABA had no effect on seed number, grain yield, water use efficiency (WUE) for grain yield or harvest index, but significantly reduced water use by $4.7 \%$ 
and increased hundred-grain weight by $4.3 \%$ (Figure 9, Table S1). Exogenous application of ABA significantly increased WUE for grain yield under well-watered $(7.6 \%)$ and moderate water stress (6.5\%; Figure 9).
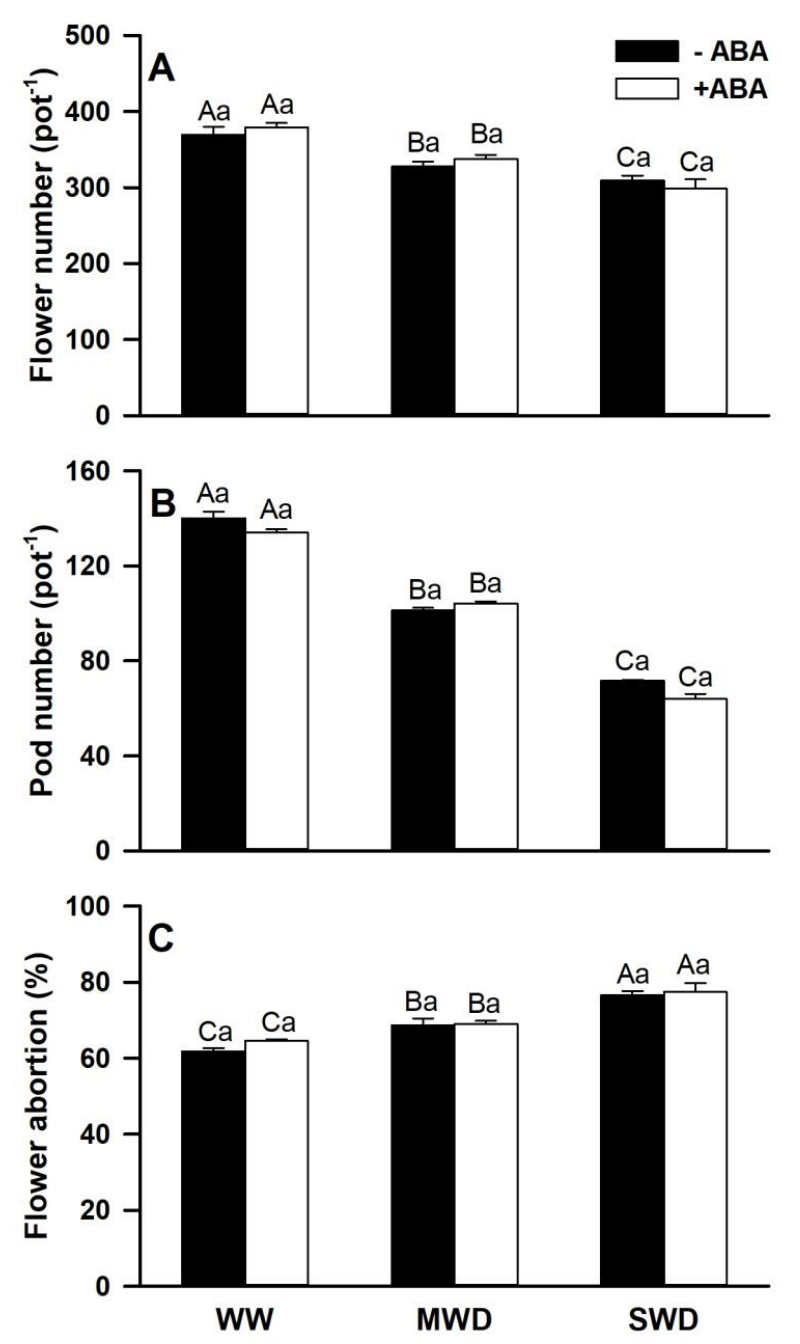

Figure 8. (A) Flower number $\left(\operatorname{pot}^{-1}\right)$, (B) pod number $\left(\operatorname{pot}^{-1}\right)$ and (C) flower abortion (\%) in the soybean cultivar Jindou 19 (JD) - with and without $10 \mu \mathrm{M}$ exogenous ABA applied one day before withholding water-at 45 days after sowing (DAS) under three water treatments (well-watered (WW): Soil water content (SWC) maintained at 70-90\% field capacity (FC); moderate water deficits (MWD): $45-55 \%$ FC and severe water deficits (SWD): $30-35 \%$ FC). Values are means \pm SE $(n=7)$. The capital and small letter indicated significantly different among the water treatment at the same ABA level and between the ABA treatment at the same water treatment at $p=0.05$, respectively. 

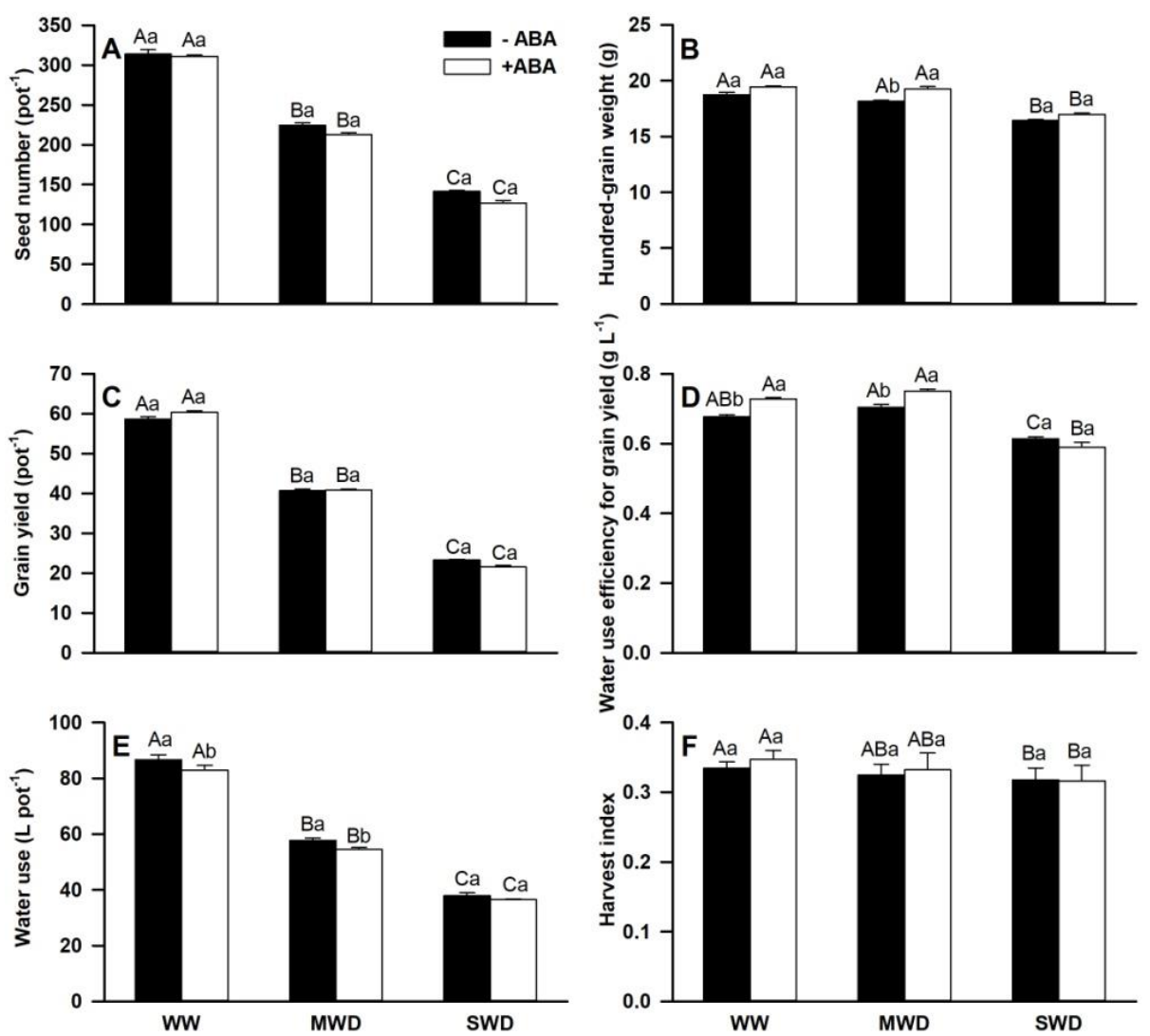

Figure 9. (A) Seed number ( pot $\left.^{-1}\right)$, (B) hundred-grain weight (g), (C) grain yield (pot $\left.{ }^{-1}\right)$, (D) water use efficiency for grain yield $\left(\mathrm{g} \mathrm{L}^{-1}\right),(\mathbf{E})$ water use $\left(\mathrm{L} \mathrm{pot}^{-1}\right)$ and $(\mathbf{F})$ harvest index in the soybean cultivar Jindou 19 (JD) —with and without $10 \mu \mathrm{M}$ exogenous ABA applied one day before withholding water-at 45 days after sowing (DAS) under three water treatments (well-watered (WW): Soil water content (SWC) maintained at 70-90\% field capacity (FC); moderate water deficits (MWD): 45-55\% FC and severe water deficits (SWD): $30-35 \%$ FC). Values are means \pm SE $(n=7)$. The capital and small letter indicated significantly different among the water treatment at the same ABA level and between the ABA treatment at the same water treatment at $p=0.05$, respectively.

\section{Discussion}

\subsection{Exogenous ABA Improved Leaf Desiccant Tolerance and RWC under Water Stress by Increasing OA}

Since leaf desiccant tolerance is reflected in the lethal $\Psi_{\text {leaf }}[24]$, the decrease by $-0.4 \mathrm{MPa}$ in the lethal $\Psi_{\text {leaf }}$ when exogenous ABA was applied, indicates that exogenous ABA improved leaf desiccant tolerance in soybean as it was previously shown in wheat [6]. However, the increase in OA by 0.3 MPa under water stress when exogenous ABA was applied indicates that the increase in OA with exogenous ABA applications was the main mechanism involved in improving leaf desiccant tolerance under water stress. Presumably, the water stress induced accumulation of solutes, such as sugars, which inceased the OA allowing further reductions in $\Psi_{\text {leaf }}$ [25].

Exogenous applications of ABA improved leaf RWC and maintained leaf photosynthetic rate during the progressive drying of the soil. This is consistent with previous findings that soybean cultivars with high OA have high leaf RWC under water stress $[9,15]$ and indicates that OA plays an important role in maintaining leaf RWC. The exogenous application of ABA could increase leaf ABA accumulation to induce stomata closure and reduce water loss to maintain leaf RWC under water stress. The other way leaf RWC was maintained was by increasing water uptake by the root system from the soil, as the high OA in the leaf allowed a further reduction in $\Psi_{\text {leaf }}$. 


\subsection{Exogenous ABA Had No Effect on Grain Yield But Increased WUE}

The role of exogenous applications of ABA in determining the yield of a crop under water stress is controversial, as some studies with wheat [7] and sunflower [8] have shown increases in grain yield. However, other studies with wheat [6] have shown that exogenous applications of ABA did not affect grain yield under water stress. In this study, exogenous application of ABA did not increase grain yield in soybean under water stess and this was associated to the $20-30 \%$ only increase in leaf ABA after the soil was drenched with exogenous ABA. In soybean as in some other grain legumes, seed number is the main determinant of seed yield $[26,27]$ and the weak but negative effect on seed number when exogenous ABA was applied under water stress explains why seed yield was not increased, despite the significant increase in the hundred-grain weight $(p=0.003)$. The increase in the hundred-grain weight compensated for the lower seed number to maintain rather than increase the grain yield. Although soybean cultivars with high OA capacity can produce high grain yield under water stress [9], the increased $\mathrm{OA}$ induced by exogenous applications of ABA under water stress did not result in seed yield increase, indicating that the main effect of exogenous ABA was to induce OA, which improved leaf desiccant tolerance but not grain yield.

Since exogenous application of ABA did not have an effect on seed yield, we compared flower number and flower abortion with or without exogenous application ABA under water stress. Water stress alone reduced flower number $(p<0.001)$ and as expected from studies with lupin $[28,29]$ and chickpea [30,31], it also increased flower abortion, presumably associated with a reduction in the time for flower development and assimilate supply [28,32]. However, applications of exogenous ABA had no effect on the number of flowers, and flower abortion under water stress. This is in disagreement with the findings of Liu et al. [33] that exogenous applications of ABA reduce flower abortion under water stress in soybean. It is likely that the difference response of flower abortion to exogenous application of ABA under water stress may be expained by the differences in the increase in leaf ABA concentration after the exogenous application of ABA. In our study it was 20-30\% only and this low concentration of leaf ABA could not induce flower abortion.

The significantly increased in WUE ${ }_{g}$ with the exogenous application of ABA under well-watered conditions and moderate water deficits (MWD; $p<0.001$ ) only, is consistent with the findings of Du et al. [6] in wheat. The increase in WUE $g$ with the exogenous application of ABA under well-watered and MWD resulted from a no effect on grain yield while water use was reduced as transpiration was limited.

\subsection{Exogenous Applications of $A B A$ Increased $W U E_{i}$ and $W U E_{\text {inst }}$ by Reducing gs}

The decrease in $g s$ and leaf transpiration rate, which significantly increased $W U E_{i}$ and $W U E_{\text {inst }}$ under well-watered conditions during the first five days after ABA was applied, indicates that exogenous application of $\mathrm{ABA}$ can affect the stomatal behavior, increasing both $\mathrm{WUE}_{\mathrm{i}}$ and $\mathrm{WUE}_{\mathrm{inst}}$, as previously showed, but under drought conditions [10,34]. However, the effect of exogenous application of $\mathrm{ABA}$ on $\mathrm{WUE}_{\mathrm{i}}$ and $\mathrm{WUE}_{\text {inst }}$ under well-watered conditions was transient.

\section{Conclusions}

The application of exogenous ABA increased leaf ABA concentration, reduced stomatal conductance and improved leaf RWC as the soil dried. It also increased OA, improving leaf desiccation tolerance as the soil progressively dried. Exogenous application of ABA had no effect on seed yield under water stress, but improved $W_{U} E_{g}$ by reducing water use under well-watered conditions and moderate soil water deficits.

Supplementary Materials: The following are available online at http://www.mdpi.com/2073-4395/9/7/395/s1, Table S1: Significance of chemical treatment (ABA), water treatment $(\mathrm{W})$ and their interactions on flower number $\left(\operatorname{pot}^{-1}\right)$, pod number $\left(\operatorname{pot}^{-1}\right)$, flower abortion $(\%)$, seed number $\left(\operatorname{pot}^{-1}\right)$, hundred-grain weight $(\mathrm{g})$, grain yield $\left(\right.$ pot $\left.^{-1}\right)$, water use efficiency for grain yield $\left(\mathrm{g} \mathrm{L}^{-1}\right)$, water use $\left(\mathrm{L} \mathrm{pot}^{-1}\right)$ and harvest index in jindou 19 (JD) with and without $10 \mu \mathrm{M}$ exogenous ABA at 45 days after sowing (DAS) under three water treatments (well-watered(WW): 
maintain soil water content between 70-90\%; moderate water deficit (MWD): maintain SWC between 45-55\% and severe water deficit (SWD): maintain SWC between 30-35\%). n.s. not significant, ${ }^{*} p<0.05,{ }^{* *} p<0.01$, and *** $p<0.001$. The values in parenthesis are the LSD at $p=0.05$.

Author Contributions: Conceptualization, J.H., Y.J. and F.-M.L.; Methodology, J.H., Y.J. and F.-M.L.; Formal Analysis, J.H., H.-Y.L. and Z.C.; Writing-Original Draft Preparation, J.H., Y.J., J.A.P. and F.-M.L.; Writing-Review and Editing, J.H., Y.J., J.A.P. and F.-M.L.; Supervision, F.-M.L.; Project Administration, F.-M.L.; Funding Acquisition, J.H. and F.-M.L.

Funding: This research was funded by the Guizhou Science and Technology Support Program Project [Qiankehezhicheng (2019) 2399], Guizhou University Introduction of Talent Research Projects [guidarenjihezi (2017) 048], the National Natural Science Foundation of China [31860115, 31700390], the Key Laboratory of Soil Quality Safety and the Regulation of Water and Fertilizer of Guizhou Province [Qianjiaohe KY 2016(001)], the Guizhou Provincial Biology First-Class Subject Construction Project [GNYL (2017) 009], the Provincial Nation-class Discipline of Biology Foundation. the '111' Programme [2007B51], the Program for Innovative Research Teams of the Ministry of Education of China [IRT_13R26], the APC was fund by Guizhou Science and Technology Support Program Project [Qiankehezhicheng (2019) 2399].

Acknowledgments: We thank the help from the UWA Institute of Agriculture at The University of Western Australia.

Conflicts of Interest: All authors declare no conflict of interest.

\section{References}

1. Koornneef, M.; Hanhart, C.J.; Hilhorst, H.W.M.; Karssen, C.M. Invivo inhibition of seed development and reserve protein accumulation in recombinants of abscisic-acid biosynthesis and responsiveness mutants in Arabidopsis-Thaliana. Plant Physiol. 1989, 90, 463-469. [CrossRef] [PubMed]

2. Wilkinson, S.; Davies, W.J. Drought, ozone, ABA and ethylene: New insights from cell to plant to community. Plant Cell Environ. 2010, 33, 510-525. [CrossRef] [PubMed]

3. Zhang, J.; Davies, W.J. Changes in the concentration of ABA in xylem sap as a function of changing soil-water status can account for changes in leaf conductance and growth. Plant Cell Environ. 1990, 13, $277-285$. [CrossRef]

4. Davies, W.J.; Zhang, J.H. Root signals and the regulation of growth and development of plants in drying soil. Annu. Rev. Plant Physiol. Plant Mol. Biol. 1991, 42, 55-76. [CrossRef]

5. Du, Y.L.; Wang, Z.Y.; Fan, J.W.; Turner, N.C.; Wang, T.; Li, F.M. $\beta$-Aminobutyric acid increases abscisic acid accumulation and desiccation tolerance and decreases water use but fails to improve grain yield in two spring wheat cultivars under soil drying. J. Exp. Bot. 2012, 63, 4849-4860. [CrossRef] [PubMed]

6. Du, Y.L.; Wang, Z.Y.; Fan, J.W.; Turner, N.C.; He, J.; Wang, T.; Li, F.M. Exogenous abscisic acid reduces water loss and improves antioxidant defence, desiccation tolerance and transpiration efficiency in two spring wheat cultivars subjected to a soil water deficit. Funct. Plant Biol. 2013, 40, 494-506. [CrossRef]

7. Travaglia, C.; Reinoso, H.; Cohen, A.; Luna, C.; Tommasino, E.; Castillo, C.; Bottini, R. Exogenous ABA increases yield in field-grown wheat with moderate water restriction. J. Plant Growth Regul. 2010, 29, 366-374. [CrossRef]

8. Hussain, S.; Saleem, M.F.; Ashraf, M.Y.; Cheema, M.A.; Haq, M.A. Abscisic acid, a stress hormone helps in improving water relations and yield of sunflower (Helianthus annuus L.) hybrids under drought. Pak. J. Bot. 2010, 42, 2177-2189.

9. He, J.; Du, Y.L.; Wang, T.; Turner, N.C.; Xi, Y.; Li, F.M. Old and new cultivars of soya bean (Glycine max L.) subjected to soil drying differ in abscisic acid accumulation, water relations characteristics and yield. J. Agron. Crop Sci. 2016, 202, 372-383. [CrossRef]

10. Gago, J.; Douthea, C.; Florez-Sarasab, I.; Escalonaa, J.M.; Galmesa, J.; Fernieb, A.R.; Flexasa, J.; Medrano, H. Opportunities for improving leaf water use efficiency under climatechange conditions. Plant Sci. 2014, 226, 108-119. [CrossRef]

11. Jones, M.M.; Turner, N.C. Osmotic adjustment in expanding and fully expanded leaves of sunflower in response to water deficits. Aust. J. Plant Physiol. 1980, 7, 181-192. [CrossRef]

12. Morgan, J.M. Osmoregulation and water-stress in higher-plants. Annu. Rev. Plant Physiol. Plant Mol. Biol. 1984, 35, 299-319. [CrossRef]

13. Turner, N.C.; Wright, G.C.; Siddique, K.H.H. Adaptation of grain legumes (pulses) to water-limited environments. Adv. Agron. 2001, 71, 193-231. 
14. Turner, N.C. Turgor maintenance by osmotic adjustment, an adaptive mechanism for coping with plant water deficits. Plant Cell Environ. 2016, 40,1-3. [CrossRef] [PubMed]

15. James, A.T.; Lawn, R.J.; Cooper, M. Genotypic variation for drought stress response traits in soybean. I. Variation in soybean and wild Glycine spp. for epidermal conductance, osmotic potential, and relative water content. Aust. J. Agric. Res. 2008, 59, 656-669. [CrossRef]

16. James, A.T.; Lawn, R.J.; Cooper, M. Genotypic variation for drought stress response traits in soybean. II. Inter-relations between epidermal conductance, osmotic potential, relative water content, and plant survival. Aust. J. Agric. Res. 2008, 59, 670-678. [CrossRef]

17. Blum, A. Osmotic adjustment is a prime drought stress adaptive engine in support of plant production. Plant Cell Environ. 2017, 40, 4-10. [CrossRef]

18. Osakabe, Y.; Arinaga, N.; Umezawa, T.; Katsura, S.; Nagamachi, K.; Tanaka, H.; Ohiraki, H.; Yamada, K.; Seo, S.U.; Abo, M.; et al. Osmotic stress responses and plant growth controlled by potassium transporters in Arabidopsis. Plant Cell 2013, 25, 609-624. [CrossRef]

19. Turner, N.C. Measurement of plant water status by the pressure chamber technique. IRRI Sci. 1988, 9, 289-308. [CrossRef]

20. Fan, X.W.; Li, F.M.; Song, L.; Xiong, Y.C.; An, L.Z.; Jia, Y.; Fang, X.W. Defense strategy of old and modern spring wheat varieties during soil drying. Physiol. Plant. 2009, 136, 310-323. [CrossRef]

21. Turner, N.C.; Abbo, S.; Berger, J.D.; Chaturvedi, S.K.; French, R.J.; Ludwig, C.; Mannur, D.M.; Singh, S.J.; Yadava, H.S. Osmotic adjustment in chickpea (Cicer arietinum L.) results in no yield benefit under terminal drought. J. Exp. Bot. 2007, 58, 187-194. [CrossRef] [PubMed]

22. He, Z. Enzyme linked Immunosorbent Assay for Endogenous Plant Hormones. In Guidance to Experiment on Chemical Control in Crop Plants; He, Z., Ed.; Beijing Agricultural University Publishers: Beijing, China, 1993; pp. 60-68.

23. Yang, J.C.; Zhang, J.H.; Wang, Z.Q.; Zhu, Q.S.; Wang, W. Hormonal changes in the grains of rice subjected to water stress during grain filling. Plant Physiol. 2001, 127, 315-323. [CrossRef] [PubMed]

24. Auge, R.M.; Kubikova, E.; Moore, J.L. Foliar dehydration tolerance of mycorrhizal cowpea, soybean and bush bean. New Phytol. 2001, 151, 535-541. [CrossRef]

25. Turner, N.C.; Jones, M.M. Turgor maintenance by osmotic adjustment: A review and evaluation. In Adaptation of Plants to Water and High Temperature Stress; Turner, N.C., Kramer, P.J., Eds.; Wiley: New York, NY, USA, 1980; pp. 87-103.

26. Sinclair, T.R. Water and nitrogen limitations in soybean grain production: I. Model development. Field Crops Res. 1986, 15, 125-141. [CrossRef]

27. Egli, D.B. Flowering, pod Set and reproductive success in Soya Bean. J. Agron. Crop Sci. 2005, 191, $283-291$. [CrossRef]

28. Palta, J.A.; Ludwig, C. Pod set and seed yield as affected by cytokininapplication and terminal drought in narrow-leafed lupin. Aust. J. Agric. Res. 1997, 48, 81-90. [CrossRef]

29. Dracup, M.; Reader, M.A.; Palta, J.A. Variation in yield of narrow-leafed lupin caused by terminal drought. Aust. J. Agric. Res. 1998, 49, 799-810. [CrossRef]

30. Leport, L.; Turner, N.C.; Davies, S.L.; Siddique, K.H.M. Variation in podproduction and abortion among chickpea cultivars under terminal drought. Eur. J. Agron. 2006, 24, 236-246. [CrossRef]

31. Fang, X.W.; Turner, N.C.; Yan, G.J.; Li, F.M.; Siddique, K.H.M. Flower numbers, pod production, pollen viability, and pistil function are reduced and flower and pod abortion increased in chickpea (Cicer arietinum L.) under terminal drought. J. Exp. Bot. 2010, 61, 335-345. [CrossRef]

32. Farooq, M.; Gogoi, N.; Barthakur, S.; Baroowa, B.; Bharadwaj, N.; Alghamdi, S.S.; Siddique, K.H.M. Drought stress in grain legumes during reproduction and grain filling. J. Agron. Crop Sci. 2017, 203, 81-102. [CrossRef] 
33. Liu, F.; Jensen, C.R.; Andersen, M.N. Pod set related to photosynthetic rate and endogenous ABA in soybeans subjected to different water regimes and exogenous ABA and BA at early reproductive stages. Ann. Bot. 2004, 94, 405-411. [CrossRef] [PubMed]

34. Fischer, R.A.; Turner, N.C. Plant productivity in the arid and semiarid zones. Annu. Rev. Plant Physiol. 1978, 29, 277-317. [CrossRef] 